\title{
Dietary habits and inadequate control of blood pressure in hypertensive adults assisted by a Brazilian Family Doctor Program
}

\author{
Bárbara da Silva Nalin de Souza ${ }^{1}$, Maria Luiza Garcia Rosa ${ }^{1, *}$, Jocemir R Lugon², \\ Edna Massae Yokoo ${ }^{1}$, Evandro Tinoco Mesquita ${ }^{2}$, Michele Rodrigues ${ }^{1}$, \\ Carolina da Silva Ramos ${ }^{1}$ and Maurício Cagy ${ }^{1}$ \\ 'Department of Epidemiology and Biostatistics, Universidade Federal Fluminense, Rua Marques do Paraná 303 \\ - 3o andar anexo, Centro, Niterói, R, Brazil, CEP 24030-210: ${ }^{2}$ Department of Clinical Medicine, \\ Medical School, Universidade Federal Fluminense, Niterói, RJ, Brazil
}

Submitted 13 July 2010: Accepted 31 March 2011: First published online 7 July 2011

\begin{abstract}
Objective: To estimate dietary habits and other factors associated with inadequate blood pressure (BP) control in hypertensive patients adherent to antihypertensive drug treatment assisted by a Brazilian Family Doctor Program (FDP).

Design: A cross-sectional study.

Setting: FDP units, Niterói, Rio de Janeiro, Brazil.

Subjects: We included data from both male and female participants aged $\geq 20$ years. Participants completed a standardized questionnaire containing questions related to demographics, socio-economic factors, comorbidities and lifestyle, as well as a validated FFQ and eleven additional qualitative questions to investigate dietary habits. Food items were divided into sixteen groups. Medical consultations were performed, BP measurements were taken, blood and urine samples were assessed and anthropometric and nutritional status was evaluated. Results: Individuals with inadequate BP control presented higher BMI values (prevalence ratio $(\mathrm{PR})=1 \cdot 027,95 \% \mathrm{CI} 1 \cdot 009,1 \cdot 045)$ and also consumed more meat $(\mathrm{PR}=1 \cdot 091,95 \%$ CI $1 \cdot 022,1 \cdot 165)$, which are potentially modifiable variables. Higher levels of serum creatinine ( $P R=1 \cdot 894,95 \%$ CI 1.241, 2.892) were also associated with inadequate BP control, as were skin colour (white). After inclusion of the $\mathrm{Na}$ excretion index, which is an indirect measure of salt intake, a slight decrease was observed in the PR for meat, which resulted in loss of statistical significance.

Conclusions: The results indicate that salt consumption, skin colour, BMI and serum creatinine are associated with inadequate BP control.
\end{abstract}

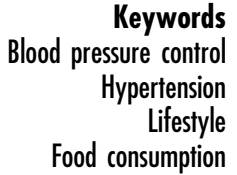

Hypertension, defined as blood pressure (BP) $\geq 140$ / $90 \mathrm{mmHg}$ or use of antihypertensive medications ${ }^{(1)}$, is a major risk factor for CVD, which is the primary cause of death in Brazil and worldwide ${ }^{(2)}$. Hypertension is prevalent in a number of countries. In Brazil, the rate varies between $22 \cdot 3 \%$ and $43 \cdot 9 \%^{(3)}$.

The main objective of treating hypertension is to reduce cardiovascular morbidity and mortality through decreased levels of $\mathrm{BP}^{(4)}$. Decision regarding whom to treat should be based on estimation of the total cardiovascular risk, not just on $\mathrm{BP}^{(5)}$.

Adoption of lifestyle changes has proven to be effective in reducing $\mathrm{BP}$ and is recommended for all patients with hypertension. Such modifications include weight control, increased physical activity, dietary restrictions, including the reduction of $\mathrm{Na}$ and increase of $\mathrm{K}$, moderation of alcohol intake and adoption of the DASH (Dietary Approaches to Stop Hypertension) diet plan that emphasizes a high intake of fruits and vegetables, complex carbohydrates, low-fat dairy products and the restriction of saturated $\mathrm{fat}^{(6)}$. Na restriction in hypertensive patients reduces $\mathrm{BP}$, but the long-term impact of reduced salt intake on $\mathrm{BP}$, mortality and morbidity remains to be defined ${ }^{(7)}$. However, the quality of diets of hypertensive Americans following the publication of the DASH diet has not improved, suggesting that secular trends have minimized the impact of the DASH message ${ }^{(8)}$.

In most hypertensive patients, drug therapy is required to achieve adequate BP levels ${ }^{(9)}$. The Lowering Treatment Trialists' Collaboration has shown that differences between 
drug classes are quite small, even across different age groups, compared with the benefits of maximizing the reduction in $\mathrm{BP}$, especially systolic blood pressure $(\mathrm{SBP})^{(5)}$. Despite the availability of various classes of antihypertensive medications, rates of BP control have remained low ${ }^{(1)}$, accounting for $<27 \%$ of patients in developed countries and for approximately $10 \%$ in developing countries ${ }^{(10)}$.

Non-compliance may have a substantial role in BP control. Patients' non-adherence to therapy is increased by misunderstanding of the condition or treatment, denial of illness because of lack of symptoms or perception of drugs as symbols of ill health, lack of patient involvement in the care plan or unexpected adverse effects of medications ${ }^{(1)}$. In addition, one of the main factors related to the control of hypertension is access to BP drugs. In Brazil, despite the presence of a government-sponsored National Health System to provide medicines, access is limited and unequal ${ }^{(11)}$. However, in some municipalities, for some highly prevalent conditions such as hypertension, particularly in certain primary care programmes, there is a more regular drug supply. An example of such a project is the Family Doctor Program (FDP) in Niterói, Rio de Janeiro, Brazil, which deals with the most disadvantaged members of society.

The present study aims to estimate dietary habits and other factors associated with inadequate BP control in hypertensive patients under treatment assisted by FDP and strengthen complementary approaches to the treatment of hypertension.

\section{Methods}

The present study used data from participants in the Cardiometabolic, Renal and Familial (CAMELIA) study, which was conducted between June 2006 and December 2007. A total of 1098 individuals were recruited from a public primary care programme, the FDP, in Niterói, Rio de Janeiro, Brazil. Thirteen FDP units were selected by convenience, covering all administrative areas of the city. Families were enrolled following an initial selection of index cases. To be accepted as an index case, individuals were required to be married to a partner who has agreed to participate in the study and to have at least one descendant between 12 and 30 years of age who would also enrol. Four groups of index cases were recruited: (i) hypertensive patients without diabetes mellitus; (ii) diabetic patients with hypertension; (iii) diabetic patients without hypertension; and (iv) patients without either hypertension or diabetes mellitus. Index cases were randomly selected from those who met the inclusion criteria. Pregnant women, people with immune deficiencies and those taking immunosuppressive agents (steroids and cytostatic drugs) were excluded from the study. The protocol was approved by the Ethics Committee of the Medical School of Universidade Federal Fluminense. Written informed consent was obtained from all participants.
After the pilot project, trained researchers visited the FDP facility in the community. The participants responded to a questionnaire that asked for information related to comorbidities and demographics, as well as information related to socio-economic and lifestyle factors. Medical staff members collected personal and family medical histories. Trained researchers measured the participants' BP and also collected fasting blood samples and first-morning urine spot samples. Dietitians assessed the participants' anthropometric and nutritional status.

BP was measured using an electronic sphygmomanometer (Hem-711AC; Omron Co., Kyoto, Japan). Three measurements were taken and the mean of the second and the third was considered. When the difference between two measurements was $>5 \mathrm{mmHg}$, an additional measurement was taken to replace one of the original values. BP at admission and the mean time of hypertension treatment were extracted from the medical records of the FDP.

The present study was cross-sectional and included data from both male and female participants who were at least 20 years old, all undergoing antihypertensive treatment. Patients were included if they responded 'yes' to the question 'Has a doctor told you that you are a hypertensive patient?' and who, in consultation with medical researchers of the study, indicated what type of antihypertensive medication they had been prescribed and reported taking the prescribed medication. In the CAMELIA study, there was 298 hypertensive patients undergoing treatment and 239 reported adhering to prescription. The number of antihypertensive drugs prescribed to the participant was self-reported to a physician during the visit. More than $80 \%$ of participants presented their prescription(s) to the researchers. Participants were classified as receiving one, two, three or more medications. The FDP does maintain a protocol for the treatment of hypertension consisting of a progressive increase in the number of BP drugs, which are freely available for patients. Inappropriate BP control was classified as $\mathrm{SBP} \geq 140 \mathrm{mmHg}$ and/or diastolic BP (DBP) $\geq 90 \mathrm{mmHg}$ at visit.

Age was considered a continuous variable in the present study. Participants were classified as white or nonwhite according to their skin colour. Marital status was defined as either living with or living without a partner. There were three categories of family monthly income: $\leq \$$ US $200 \cdot 00 ;>\$$ US $200 \cdot 00$ to $\leq \$$ US $400 \cdot 00$; and $>\$$ US $400 \cdot 00$ (the minimum wage per month in Rio de Janeiro at the time was approximately \$US 200•00). Participants were classified by educational level into three strata: low (never studied or studied up to the 4th grade); intermediate (5th-8th grades); and high (secondary school and beyond). Participants also completed a questionnaire on leisure-time physical activity that contained questions about physical activities performed during the past $15 \mathrm{~d}$ detailing the type of activity, the number of times the activity was performed per week and the time spent on 
the activity ${ }^{(12)}$. Those who reported engaging in $<150$ min of physical activity in their leisure time ${ }^{(13)}$ were considered physically inactive. Participants were classified as nonsmokers, ex-smokers or current smokers. Food consumption was estimated using an $\mathrm{FFQ}^{(14)}$. Food groups were proposed by Nettleton et al. ${ }^{(15)}$ and adjusted by dietitians who worked on the research project. To calculate the daily intake of each food group, the frequency reported was converted to daily values. The values of daily intake multiplied by the serving of each item consumed equalled the number of servings consumed per day from each food group. Participants provided information about their use of table salt in the questionnaire by choosing 'never add', 'taste and add if necessary' or 'add always'. Changes in dietary patterns were ascertained on the basis of a yes or no question in the FFQ: 'Have you ever changed your dietary pattern in your adult life?'. Each participant's family history of hypertension was assessed on the basis of whether he or she classified his or her father and/or mother as being hypertensive.

Individuals with a self-reported medical diagnosis of diabetes were classified as such in the study. Dyslipidaemia was considered present when the total levels of cholesterol ( $\geq 200 \mathrm{mg} / \mathrm{dl})$, LDL $(\geq 130 \mathrm{mg} / \mathrm{dl}$ ), HDL (for men $<40 \mathrm{mg} / \mathrm{dl}$ and for women $<50 \mathrm{mg} / \mathrm{dl}$ ) or TAG $(\geq 150 \mathrm{mg} / \mathrm{dl})$ were altered ${ }^{(16)}$. Each participant's weight was measured using an electronic digital scale (PL80, Filizola S/A, Brazil) and height was measured using a portable digital stadiometer (Kirchnner \& Wilhelm, Medizintechnik, Germany). BMI was calculated as weight in kilograms divided by the square of height in metres $\left(\mathrm{kg} / \mathrm{m}^{2}\right)$ and was considered as a continuous variable. Biochemical analyses were performed using a chemistry analyser (Selectra; Vital Scientific NE, the Netherlands).

Uric acid $(\mathrm{mg} / \mathrm{dl})$, fasting glucose $(\mathrm{mg} / \mathrm{dl})$ and creatinine $(\mathrm{mg} / \mathrm{dl})$ were analysed as continuous variables. The estimated glomerular filtration rate was calculated using the equation developed in the study Modification of Diet in Renal Disease $($ MDRD $)=170 \times($ creatinine $)-0.999 \times($ age $)$ $-0 \cdot 176 \times[(20 / 60 \times$ urea $)-0 \cdot 17] \times($ albumin $) \times 0 \cdot 318 \times$ $0 \cdot 762$ (if female), a formula validated for this purpose ${ }^{(17)}$, and was analysed continuously. $\mathrm{Na}$ intake was estimated by determining the rate of excretion of $\mathrm{Na}$ ([ $\mathrm{Na}$ in $\mathrm{mEq} / \mathrm{l}$ in the sample of urine/urinary creatinine in $\mathrm{mg} \%] \times 100$ ) expressed in $\mathrm{mEq} \mathrm{Na/g}$ creatinine and was also analysed continuously $^{(18)}$. Participants were classified as having a history of myocardial infarction, cerebrovascular accidents or congestive heart failure when they responded affirmatively to a question about whether their doctor had ever diagnosed them with those conditions.

\section{Statistical analysis}

For data analysis, we used the Statistical Package for the Social Sciences statistical software package version $17 \cdot 0$ (SPSS Inc., Chicago, IL, USA). Crude and adjusted prevalence ratios (PR) were calculated to estimate the association between adequate control or inadequate control of BP and other variables. Bivariate and multivariate analyses were performed using the model of generalized estimating equations, which is suitable for non-independent observations, since the unit for inclusion in the original study was each family. Multivariate analysis was carried out stepby-step through the progressive inclusion of independent variables that could influence inadequate BP control. Variables with a statistical significance level $<0 \cdot 10$ were retained in subsequent models. In model 1 , sociodemographic and lifestyle factors, clinical and biochemical metabolic parameters and time of treatment were included. In models 2-4, food groups were included individually. The final model included food groups and other variables that had $P<0 \cdot 10$, and also included the rate of $\mathrm{Na}$ excretion. Statistical significance with $P$ value $<0.05$ was adopted in the final model. Factors associated with the control of BP may in fact be risk factors, such as demographic, socio-economic or lifestyle factors, and comorbidities (obesity and high uric acid) or outcomes such as myocardial infarction, stroke, heart failure and elevated creatinine. To facilitate analysis, all were considered as independent variables.

\section{Results}

The study sample consisted of 239 participants (53\% were women) and comprised mostly individuals with intermediate schooling, family income >\$US 400.00, non-white and with a partner (Table 1 ). The prevalence of inadequate BP control was $51.5 \%$; for SBP alone the prevalence was $43 \cdot 5 \%$ and for DBP alone it was $33 \cdot 1 \%$ (data not shown). The mean time of treatment was $7 \cdot 6$ (sD $6 \cdot 7)$ years, varying from $1(10 \%)$ to $>10$ years $(29 \%)$. Approximately $20 \%$ of participants reported smoking currently. Many of the participants reported already having made some changes to their diet, and only a minority said that they regularly added salt at the table. Most were not diabetic and were free of other metabolic disorders, nor did they have a history of CVD (Table 1).

Most participants indicated the drugs they were using by presenting prescriptions at the time of medical consultation with the study investigators. Of those who said they used diuretics, $85.9 \%$ had a prescription; $86.0 \%$ had a prescription for $\beta$-blockers; $79.9 \%$ had a prescription for angiotensin-converting enzyme inhibitors (ACEI); and $83 \cdot 8 \%$ had a prescription for other classes. Approximately $12 \%$ made use of three antihypertensive drugs; $43.9 \%$ used two antihypertensive drugs and $43.9 \%$ used one.

The crude PR of inadequate BP control is shown in Table 1. Skin colour (white), marital status (without a partner), physical activity (inactive), BMI, glucose, creatinine levels, SBP value at admission to the FDP, time of treatment and the consumption of 'red meat, processed and preserved in salt' and 'other alcoholic beverages' were shown to be 
Table 1 Characteristics of participants and crude PR and $95 \% \mathrm{Cl}$ of adequate and inadequate control of BP groups

\begin{tabular}{|c|c|c|c|c|c|c|c|}
\hline \multirow[b]{2}{*}{ Variable } & \multicolumn{2}{|c|}{ Adequate control ( $n$ 116) } & \multicolumn{2}{|c|}{ Inadequate control ( $n$ 123) } & \multirow[b]{2}{*}{ PR } & \multirow[b]{2}{*}{$95 \% \mathrm{Cl}$} & \multirow[b]{2}{*}{$P$ value } \\
\hline & $n$ or mean & $\%$ or SD & $n$ or mean & $\%$ or SD & & & \\
\hline \multicolumn{8}{|l|}{$\begin{array}{l}\text { Demographic and socio-economic } \\
\text { factors }\end{array}$} \\
\hline \multicolumn{8}{|l|}{ Sex } \\
\hline Female & 66 & $56 \cdot 9$ & 60 & $48 \cdot 8$ & 1 & & \\
\hline Male & 50 & $43 \cdot 1$ & 63 & $51 \cdot 2$ & $1 \cdot 171$ & $0.919,1.491$ & $0 \cdot 202$ \\
\hline Age (years)* & $49 \cdot 56$ & 8.94 & $49 \cdot 67$ & $9 \cdot 60$ & $1 \cdot 001$ & $0.987,1.015$ & 0.932 \\
\hline \multicolumn{8}{|l|}{ Skin colourt } \\
\hline Non-white & 87 & $75 \cdot 7$ & 79 & $64 \cdot 2$ & 1 & & \\
\hline White & 28 & $24 \cdot 3$ & 44 & $35 \cdot 8$ & $1 \cdot 284$ & $1 \cdot 002,1 \cdot 645$ & $0 \cdot 048$ \\
\hline \multicolumn{8}{|l|}{ Educational levelt } \\
\hline Low & 39 & $33 \cdot 6$ & 52 & $42 \cdot 3$ & 1 & & \\
\hline Intermediate & 53 & $45 \cdot 7$ & 46 & $37 \cdot 4$ & $0 \cdot 813$ & $0.618,1.069$ & $0 \cdot 139$ \\
\hline High & 24 & $20 \cdot 7$ & 25 & $20 \cdot 3$ & 0.893 & $0 \cdot 648,1 \cdot 231$ & 0.489 \\
\hline \multicolumn{8}{|l|}{ Family income/month (\$US)† } \\
\hline$\leq 200 \cdot 00$ & 11 & $9 \cdot 5$ & 14 & $11 \cdot 4$ & 1 & & \\
\hline $201 \cdot 00-400 \cdot 00$ & 31 & $26 \cdot 7$ & 33 & $26 \cdot 8$ & 0.921 & $0.597,1.420$ & 0.709 \\
\hline$>400 \cdot 00$ & 74 & $63 \cdot 8$ & 76 & $61 \cdot 8$ & 0.905 & $0.614,1.333$ & 0.613 \\
\hline \multicolumn{8}{|l|}{ Marital statust } \\
\hline With a partner & 111 & $96 \cdot 5$ & 113 & $91 \cdot 9$ & 1 & & \\
\hline Without a partner & 4 & 3.5 & 10 & $8 \cdot 1$ & $1 \cdot 416$ & $0.977,2 \cdot 051$ & 0.066 \\
\hline Lifestyle factors & & & & & & & \\
\hline Tobacco & & & & & & & \\
\hline Non-smoker & 54 & $47 \cdot 4$ & 59 & $48 \cdot 4$ & 1 & & \\
\hline Ex-smoker & 37 & $32 \cdot 5$ & 39 & 32 & 0.983 & $0 \cdot 743,1 \cdot 300$ & 0.903 \\
\hline Current smoker & 23 & $20 \cdot 1$ & 24 & $19 \cdot 6$ & 0.978 & $0 \cdot 701,1 \cdot 364$ & 0.896 \\
\hline Table salt use & & & & & & & \\
\hline Never add & 98 & $85 \cdot 2$ & 96 & $78 \cdot 7$ & 1 & & \\
\hline Taste and add if necessary & 13 & $11 \cdot 3$ & 20 & $16 \cdot 4$ & $1 \cdot 225$ & $0.905,1.658$ & $0 \cdot 189$ \\
\hline Add always & 4 & 3.5 & 6 & 4.9 & $1 \cdot 213$ & $0.718,2 \cdot 048$ & 0.471 \\
\hline Physical activity (min/week) & & & & & & & \\
\hline$>150$ & 41 & $35 \cdot 3$ & 27 & 22 & 1 & & \\
\hline$\leq 150$ & 75 & $64 \cdot 7$ & 96 & 78 & $1 \cdot 414$ & $1 \cdot 020,1.959$ & 0.037 \\
\hline Intentional diet changes & & & & & & & \\
\hline Yes & 75 & $65 \cdot 2$ & 75 & $61 \cdot 5$ & 1 & & \\
\hline No & 40 & $34 \cdot 8$ & 47 & $38 \cdot 5$ & $1 \cdot 080$ & $0.847,1.378$ & 0.533 \\
\hline Comorbiditiest & & & & & & & \\
\hline Myocardial infarction & & & & & & & \\
\hline No & 111 & $95 \cdot 7$ & 115 & 93.5 & 1 & & \\
\hline Yes & 5 & $4 \cdot 3$ & 8 & $6 \cdot 5$ & $1 \cdot 209$ & $0 \cdot 772,1 \cdot 896$ & 0.407 \\
\hline Stroke & & & & & & & \\
\hline No & 111 & $95 \cdot 7$ & 114 & $92 \cdot 7$ & 1 & & \\
\hline Yes & 5 & $4 \cdot 3$ & 9 & $7 \cdot 3$ & $1 \cdot 269$ & $0 \cdot 839,1.920$ & $0 \cdot 260$ \\
\hline Heart failure & & & & & & & \\
\hline No & 110 & $94 \cdot 8$ & 116 & $94 \cdot 3$ & 1 & & \\
\hline Yes & 6 & $5 \cdot 2$ & 7 & $5 \cdot 7$ & $1 \cdot 049$ & $0 \cdot 627,1.755$ & $0 \cdot 855$ \\
\hline $\begin{array}{l}\text { Clinical and biochemical metabo } \\
\text { parameters }\end{array}$ & & & & & & & \\
\hline Diabetest & & & & & & & \\
\hline No & 91 & $78 \cdot 4$ & 89 & $72 \cdot 4$ & 1 & & \\
\hline Yes & 25 & $21 \cdot 6$ & 34 & $27 \cdot 6$ & $1 \cdot 165$ & $0.899,1.511$ & $0 \cdot 247$ \\
\hline BMI $\left(\mathrm{kg} / \mathrm{m}^{2}\right)^{*}$ & $28 \cdot 62$ & $5 \cdot 42$ & $29 \cdot 89$ & $6 \cdot 10$ & $1 \cdot 017$ & $1 \cdot 000,1 \cdot 035$ & 0.048 \\
\hline Dislipidaemiał & & & & & & & \\
\hline No & 28 & $28 \cdot 6$ & 23 & $22 \cdot 8$ & 1 & & \\
\hline Yes & 70 & $71 \cdot 4$ & 78 & $77 \cdot 2$ & $1 \cdot 169$ & $0 \cdot 818,1 \cdot 670$ & 0.392 \\
\hline Creatinine $(\mathrm{mg} / \mathrm{dll})^{*}$ & 0.88 & $0 \cdot 21$ & 0.94 & 0.31 & 1.473 & $1 \cdot 051,2 \cdot 063$ & 0.024 \\
\hline Glucose $(\mathrm{mg} / \mathrm{dl})^{\star}$ & $109 \cdot 28$ & $32 \cdot 30$ & $120 \cdot 55$ & $42 \cdot 19$ & $1 \cdot 003$ & $1.000,1.006$ & 0.027 \\
\hline Uric acid $(\mathrm{mg} / \mathrm{dl})^{*}$ & 5.04 & 1.53 & $5 \cdot 02$ & $1 \cdot 60$ & 0.997 & $0.916,1.086$ & 0.954 \\
\hline $\begin{array}{l}\text { Glomerular filtration rate } \\
\left(\mathrm{ml} / \mathrm{min} \text { per } 1.73 \mathrm{~m}^{2}\right)^{\star}\end{array}$ & $95 \cdot 68$ & $26 \cdot 35$ & $93 \cdot 39$ & $32 \cdot 96$ & 0.999 & $0.993,1.004$ & 0.637 \\
\hline $\begin{array}{l}\mathrm{Na} \text { excretion index }(\mathrm{mEq} / \mathrm{g})^{*} \\
\mathrm{BP} \text { at admission on } \mathrm{FDP}^{\star}\end{array}$ & $143 \cdot 00$ & $80 \cdot 00$ & $173 \cdot 00$ & $154 \cdot 00$ & $1 \cdot 081$ & $1 \cdot 026,1 \cdot 139$ & 0.003 \\
\hline SBP & $134 \cdot 15$ & $19 \cdot 95$ & $140 \cdot 90$ & $23 \cdot 83$ & $1 \cdot 008$ & $1 \cdot 002,1 \cdot 014$ & 0.011 \\
\hline DBP & $88 \cdot 80$ & $16 \cdot 07$ & $88 \cdot 15$ & $16 \cdot 54$ & 0.999 & $0.989,1.008$ & $0 \cdot 764$ \\
\hline Time of treatment ${ }^{*}$ & $6 \cdot 56$ & $6 \cdot 58$ & 8.99 & $6 \cdot 63$ & $1 \cdot 027$ & $1 \cdot 005,1 \cdot 050$ & $0 \cdot 016$ \\
\hline BP medications§ & & & & & & & \\
\hline 1 & 53 & $45 \cdot 7$ & 52 & $42 \cdot 3$ & 1 & & \\
\hline 2 & 49 & $42 \cdot 2$ & 56 & $45 \cdot 5$ & $1 \cdot 077$ & $0 \cdot 825,1 \cdot 405$ & 0.585 \\
\hline$\geq 3$ & 14 & $12 \cdot 1$ & 15 & $12 \cdot 2$ & $1 \cdot 044$ & $0.711,1.533$ & $0 \cdot 824$ \\
\hline
\end{tabular}


Table 1 Continued

\begin{tabular}{|c|c|c|c|c|c|c|c|}
\hline \multirow[b]{2}{*}{ Variable } & \multicolumn{2}{|c|}{ Adequate control ( $n$ 116) } & \multicolumn{2}{|c|}{ Inadequate control (n 123) } & \multirow[b]{2}{*}{ PR } & \multirow[b]{2}{*}{$95 \% \mathrm{Cl}$} & \multirow[b]{2}{*}{$P$ value } \\
\hline & $n$ or mean & $\%$ or SD & $n$ or mean & $\%$ or SD & & & \\
\hline \multicolumn{8}{|c|}{ Family history of hypertensiont } \\
\hline No, for both parents & 38 & $32 \cdot 8$ & 40 & $32 \cdot 5$ & 1 & & \\
\hline Yes, for one parent & 52 & $44 \cdot 8$ & 52 & $42 \cdot 3$ & 0.975 & $0 \cdot 728,1 \cdot 306$ & 0.865 \\
\hline Yes, for both parents & 26 & $22 \cdot 4$ & 31 & $25 \cdot 2$ & $1 \cdot 061$ & $0 \cdot 767,1 \cdot 466$ & 0.722 \\
\hline
\end{tabular}

PR, prevalence ratio; BP, blood pressure; FDP, Family Doctor Program; SBP, systolic BP; DBP, diastolic BP.

${ }^{*}$ Data are represented as mean and SD.

tSelf-reported.

‡Dyslipidaemia was present if the total levels of cholesterol ( $\geq 200 \mathrm{mg} / \mathrm{dl}$ ), LDL ( $\geq 130 \mathrm{mg} / \mathrm{dl}$ ), HDL (for men $<40 \mathrm{mg} / \mathrm{dl}$ and for women $<50 \mathrm{mg} / \mathrm{dl}$ ) or TAG $(\geq 150 \mathrm{mg} / \mathrm{dl})$ were altered.

$\S$ According to prescription.

Table 2 Median with IQR of daily serving consumption of food groups and PR and $95 \% \mathrm{Cl}$ of inadequate control of $\mathrm{BP}$

\begin{tabular}{|c|c|c|c|c|c|}
\hline Food group & Median & IQR & PR & $95 \% \mathrm{Cl}$ & $P$ value \\
\hline Fruits & $3 \cdot 62$ & $3 \cdot 80$ & 0.985 & $0.946,1.026$ & 0.471 \\
\hline Vegetables & $9 \cdot 33$ & $6 \cdot 50$ & 0.972 & $0.942,1.002$ & 0.065 \\
\hline Read meat, processed and preserved in salt & $1 \cdot 41$ & $1 \cdot 22$ & 1.096 & $1 \cdot 038,1 \cdot 158$ & 0.001 \\
\hline Chicken and fish & $1 \cdot 19$ & $1 \cdot 00$ & $1 \cdot 024$ & $0.904,1 \cdot 159$ & 0.714 \\
\hline Beer & 0.00 & 0.29 & $1 \cdot 038$ & $0.912,1 \cdot 180$ & 0.573 \\
\hline Other alcoholic beverages & 0.00 & 0.00 & $1 \cdot 116$ & $1 \cdot 018,1 \cdot 223$ & 0.019 \\
\hline Caffeinated drinks & $2 \cdot 00$ & $1 \cdot 79$ & $1 \cdot 029$ & $0 \cdot 956,1 \cdot 108$ & 0.440 \\
\hline Sweets, sugar and sugary drinks & 3.53 & $4 \cdot 36$ & 1.009 & $0.972,1.046$ & 0.644 \\
\hline Whole dairy products & 0.99 & $1 \cdot 73$ & 0.971 & $0.883,1.067$ & 0.540 \\
\hline Low-fat dairy products & 0.00 & 0.00 & 1.072 & $0.979,1.175$ & $0 \cdot 134$ \\
\hline Wholegrain foods & 0.00 & 0.00 & 0.879 & $0.731,1.057$ & $0 \cdot 171$ \\
\hline Breads, cookies and pasta & $4 \cdot 68$ & $3 \cdot 68$ & $1 \cdot 012$ & $0.979,1.047$ & 0.480 \\
\hline Oils, fats and fried foods & $1 \cdot 17$ & $1 \cdot 77$ & 0.980 & $0 \cdot 872,1 \cdot 102$ & 0.735 \\
\hline Rice and beans & $8 \cdot 00$ & $3 \cdot 64$ & $1 \cdot 017$ & $0.970,1.066$ & 0.482 \\
\hline Canned foods & 0.67 & $0 \cdot 70$ & 1.087 & $0 \cdot 538,2 \cdot 196$ & $0 \cdot 817$ \\
\hline Eggs & $0 \cdot 14$ & 0.29 & 0.967 & $0.691,1.353$ & $0 \cdot 845$ \\
\hline
\end{tabular}

IQR, interquartile range; PR, prevalence ratio; $\mathrm{BP}$, blood pressure.

positively associated with inadequate BP control $(P<0 \cdot 10)$. The consumption of 'vegetables' was negatively associated with inadequately controlled BP (Table 2).

Model 1 included skin colour, physical activity, marital status, BMI, serum creatinine and glucose levels, SBP value at the time of admission to the FDP and time of treatment, which had a significance level $<0 \cdot 10$ in the bivariate analysis. In this initial model, marital status, glucose, SBP value at the time of admission to the FDP and time of treatment lost statistical significance. In model 2 , vegetable consumption and physical activity were not associated with the control of BP. In model 3, consumption of red meat showed a positive association with inadequately controlled BP. In model 4 , the consumption of other alcoholic beverages was not associated with the control of BP. In model 5, however, the addition of the $\mathrm{Na}$ excretion rate resulted in a loss of statistical significance for the red meat food groups (Table 3).

\section{Discussion}

In the present study, we observed a higher prevalence of inadequate BP control, independent of possible confounding variables, in hypertensive patients with higher BMI values and also in those who consumed more meat and alcohol, all potentially modifiable variables. Higher serum creatinine, BMI and skin colour (white) were also factors associated with inadequate BP control. After the inclusion of the $\mathrm{Na}$ excretion index in the final model, a loss of statistical significance was observed for red meat consumption, indicating that a part of the association between meat consumption and BP control could be explained by the consumption of salt.

The prevalence of inadequate control of $\mathrm{BP}$ in the present study was approximately $50 \%$ lower than that of other Brazilian cities, including Passo Fundo $(80 \%)^{(19)}$ and Catanduva $(72 \cdot 4 \%)^{(20)}$, and of other regions such as the USA $(71 \%)$ and Europe $(\sim 90 \%)^{(21)}$. However, it was higher than the rates reported by Mejía-Rodríguez et al. $^{(22)}$ in Mexico ( 39\%) in a study also involving participants treated in care programmes of family medicine. Continuous monitoring and free access to medication may explain the lower prevalence of inappropriate BP control.

Somewhat surprisingly, in our study, the prevalence of inadequate control was higher in whites, before and after adjustment. A contrary association was observed in a 
multiethnic study conducted among several communities in the USA. When compared with whites, all non-whites including African Americans, Chinese and Hispanics had a higher prevalence of inadequate control ${ }^{(23)}$. A part of the observed association in the USA can be explained by poorer access to health services and medicines among non-whites because whites are not socially disadvantaged. Such differences were not observed in the present study.

Age was not associated with inadequate control of BP in the present study, contrary to findings by Knight et $a l^{(24)}$ in the USA and by Roux et $a l^{(25)}$ in France. In both studies increased age was associated with greater prevalence of inadequate control. Again, the fact that patients in the present study had continuous follow-ups may have favoured the control of risk factors and the actual BP measurements, contributing to the lack of correlation between inadequate control and advanced age.

Hypertensive patients without a partner had a higher prevalence of inadequate control of $\mathrm{BP}$, in a statistically significant association, only before adjustment. One possible explanation could be the host family because the presence of a partner may provide an incentive to take medications and, of special importance for our study, contribute to compliance to recommendations regarding both diet and physical activity ${ }^{(26)}$. Consistent with this interpretation, the prevalence of a raised $\mathrm{Na}$ excretion index was higher for patients without a partner (data not shown).

Physically inactive patients had a higher frequency of inadequate control, but the adjustment by other variables resulted in a loss of statistical significance. The role of physical activity in the control of hypertension cannot be ignored $^{(27)}$. However, in a cross-sectional study such as the present one it is not possible to ascertain whether a deficiency in physical activity contributed to a failure to control BP or whether participants in whom BP was not controlled were less likely to partake in physical activities. Physical inactivity is related to weight gain. A systematic review has shown that individuals performing regular physical activities tend to gain less weight and to be less overweight and obese ${ }^{(28)}$. This may explain the high prevalence of inadequate control of BP among individuals who had increased BMI, before and after adjustment, similar to that reported by Mejía-Rodríguez $e t a l .{ }^{(22)}$. It is known that reducing weight contributes to BP control and allows for reducing the dosage of antihypertensive drugs in hypertensive patients ${ }^{(29)}$.

Despite the fact that the prevalence of hypertensive patients with inadequately controlled BP was higher in diabetics, the association was not statistically significant. Results from the Multiple Risk Factor Intervention Trial indicate that diabetes confers an increased cardiovascular risk when compared with other risk factors, suggesting that BP control should be stricter in the presence of diabetes $^{(30)}$. Since then, the guidelines for hypertension 
recommend the maintenance of lower BP in this population. In populations monitored by care programmes for families (e.g. the case study presented here), it is expected that the actions taken for the control of BP in diabetics are more intense, which may explain the minor difference in the prevalence of inappropriate $\mathrm{BP}$ control compared with non-diabetics. However, among those who had elevated fasting glucose levels without a previous diagnosis of diabetes, BP control was poorer, perhaps because of lower level of health monitoring. Studies have shown that the incidence of diabetes is higher in hypertensive patients with inadequate $\mathrm{BP}$ control $^{(31,32)}$, which points to the importance of giving special attention to the control of BP, even without a diagnosis of diabetes.

Individuals with higher serum creatinine levels had a higher prevalence of inadequate control, both in crude analysis and after adjustment. This finding was also reported by Mejía-Rodríguez et al. ${ }^{(22)}$ in Mexico and by Coresh et $a l .{ }^{(33)}$ in the USA. The explanation suggested in the two studies was a reduction in the glomerular filtration rate. In the present study, no association was observed between the levels of glomerular filtration rate estimated by the MDRD equation and BP control, perhaps because of the fact that the vast majority of the values of this variable lie within normal limits. A definitive explanation for the positive association between creatinine and BP levels is not available. However, this finding aligns with the fact that African Americans have recorded higher mean serum creatinine and a higher prevalence of hypertension compared with white Americans who do not have lower glomerular filtration rates ${ }^{(34)}$.

A study conducted among Americans identified a higher prevalence of inadequate control in hypertensive patients who used two or more drugs. For the authors, the more difficult the BP control, is the greater the number of medications used $^{(24)}$. When BP control is not achieved with a drug, an increased dose or combining with an antihypertensive from another class is usually recommended. If the goal is not reached, the addition of two or more medications is recommended ${ }^{(3)}$. In the study reported here, individuals who reported using one antihypertensive medication had a prevalence of inadequate control similar to those who reported using two or more drugs. The results may indicate that the treatment was not optimal. Diuretics, $\beta$-blockers, ACEI and other classes have similar effects on $\mathrm{BP}$, although there are differences between patients ${ }^{(35)}$. In most patients, two or more antihypertensive medications are needed to achieve the control of $\mathrm{BP}^{(9)}$. However, studies have suggested that 'medical inertia', that is, a failure to start or enhance medication when it is necessary to do so, may contribute to poor BP control ${ }^{(36,37)}$.

The prevalence of inadequate control of BP was lower among those who never added salt at the table, although the association was not statistically significant. However, both crude and adjusted analyses showed a positive association between the $\mathrm{Na}$ excretion index and inadequate
$\mathrm{BP}$ control. The reduction of $\mathrm{Na}$ intake is associated with both decreased SBP and $\operatorname{DBP}^{(9,38)}$ and with decreased mortality. The benefits would have the same magnitude if $\mathrm{Na}$ intake was reduced by only $1 \mathrm{~g} / \mathrm{d}^{(39)}$. A recent comprehensive review addressing the issue of the impact of salt restriction on BP control concluded that a lower dietary salt intake may help patients stop BP medications while maintaining good control ${ }^{(7)}$. In Brazil, the intake of this nutrient greatly exceeds the maximum levels recommended; this finding is true in all regions and across all income strata ${ }^{(40)}$.

There was a higher prevalence of inadequate control of BP in the present study among those who consumed fewer vegetables, as well as among those who consumed more meat and alcohol. After adjusting for confounding variables, including the rate of $\mathrm{Na}$ excretion, both lost statistical significance. Steffen et $a l^{(41)}$ found that vegetable consumption was inversely proportional to the elevation of BP, whereas red meat consumption had negative effects on the control of hypertension after adjustment. Wakabayashi ${ }^{(42)}$ observed that reducing the intake of alcohol caused a reduction in BP in treated hypertensive patients.

The present study has some limitations. Caution should always be exercised when dealing with cross-sectional studies. The participation rate was approximately $56 \%$, leading to a possible selection bias. This percentage was similar to that of other studies ${ }^{(43,44)}$. The reasons for nonattendance given by participants were that they had to work on the day that data collection was carried out, that they had not fasted as required or had consumed alcohol the day before the visit. The highest percentage of missing participants was among young men. One can thus assume that individuals experiencing greater difficulty in $\mathrm{BP}$ control as a result of poor adherence to treatment are under-represented in this sample. However, this observation does not affect the associations between inadequate control of BP and risk factors. It is unlikely that individuals with inadequate control of BP with low adherence to treatment have a higher prevalence of healthy lifestyles. The percentage of missing data of biochemical measurements was $16 \cdot 7$. This occurred because of difficulty in processing the samples, and since they were not related to patient characteristics they were considered random losses. It should be emphasized that the FFQ has some disadvantages as well, such as forgetfulness or omission of information, which may contribute to under- or overestimation of results ${ }^{(45)}$. The results observed in the present study are for adults served by the FDP, residents of socially disadvantaged communities, intermingled and mostly married or living with partners. We believe that the estimated associations would be even greater in a population with a similar socio-economic profile that was not covered by a family medicine programme and that does not have a predominance of adults living with companions. 


\section{Conclusion}

Inadequate control of $\mathrm{BP}$ in patients who were taking antihypertensive drugs, even in a community assisted by a primary care programme, showed statistically significant and independent association with the modifiable factors: salt intake and obesity. Inadequate BP control was also associated with skin colour and serum creatinine. Although the prevalence of inadequate control of BP was lower than that of other populations, the results of the present study indicate that the lifestyle of the population studied, despite the monitoring by the FDP, does not match the recommendations for control of hypertension, especially with regard to salt intake.

\section{Acknowledgements}

The present study was supported by the Fundação Municipal de Saúde de Niterói, the Fundação de Amparo à Pesquisa do Estado do Rio de Janeiro and the Conselho Nacional de Desenvolvimento Científico e Tecnológico. The authors have no conflict of interest to declare. B.S.N.S. was responsible for patient recruitment, screening, data entry, data interpretation and data analysis and contributed towards preparation of the manuscript; M.L.G.R. was responsible for protocol design, patient recruitment, screening, data entry, data interpretation, analysis, trial supervision and regulatory procedures and contributed to preparation of the manuscript; J.R.L. was responsible for analysis and data interpretation and contributed towards preparation of the manuscript; E.M.Y. was responsible for patient recruitment, screening and data interpretation and also contributed to preparation of the manuscript; E.T.M. was responsible for analysis and data interpretation and contributed to preparation of the manuscript; M.R. and C.S.R. were responsible for patient recruitment, screening and trial management; M.C. was responsible for protocol design, statistical analyses and data interpretation. All authors read and approved the final version of the manuscript.

\section{References}

1. Chobanian AV, Bakris GL, Black HR et al. (2003) Seventh report of the Joint National Committee on Prevention, Detection, Evaluation, and Treatment of High Blood Pressure. Hypertension 42, 1206-1252.

2. Kearney PM, Whelton M, Reynolds K et al. (2005) Global burden of hypertension: analysis of worldwide data. Lancet 365, 217-223.

3. Mion Júnior D, Junior OK, Gomes MAM et al. (2006) $V$ Diretrizes Brasileiras de Hipertensão Arterial. São Paulo: Sociedade Brasileira de Hipertensão, Sociedade Brasileira de Cardiologia.

4. Pignone M \& Mulrow CD (2001) Using cardiovascular risk profiles to individualise hypertensive treatment. BMJ 322, 1164-1166.

5. Chalmers J \& Arima H (2009) Management of hypertension: evidence from the Blood Pressure Lowering Treatment
Trialists' Collaboration and from major clinical trials. Pol Arch Med Wewn 119, 373-380.

6. Appel LJ, Moore TJ, Obarzanek E et al. (1997) A clinical trial of the effects of dietary patterns on blood pressure. DASH Collaborative Research Group. N Engl J Med 336, 1117-1124.

7. Dumler F (2009) Dietary sodium intake and arterial blood pressure. J Ren Nutr 19, 57-60.

8. Mellen PB, Gao SK, Vitolins MZ et al. (2008) Deteriorating dietary habits among adults with hypertension: DASH dietary accordance, NHANES 1988-1994 and 1999-2004. Arch Intern Med 168, 308-314.

9. Chobanian AV (2009) The hypertension paradox - more uncontrolled disease despite improved therapy. $N$ Engl J Med 361, 878-887.

10. Pereira M, Lunet N, Azevedo A et al. (2009) Differences in prevalence, awareness, treatment and control of hypertension between developing and developed countries. $J$ Hypertens 27, 963-975.

11. Guerra AA Jr, Acúrcio FA, Gomes CAP et al. (2004) Disponibilidade de medicamentos essenciais em duas regiões de Minas Gerais, Brasil. Rev Panam Salud Publica 15, 168-175.

12. Salles-Costa R, Werneck GL, Lopes CL et al. (2003) Associação entre fatores sócio-demográficos e prática de atividade física de lazer no Estudo Pró-Saúde. Cad Saude Publica 19, 1095-1105.

13. Haskell WL, Lee IM, Pate RR et al. (2007) Physical activity and public health: updated recommendation for adults from the American College of Sports Medicine and the American Heart Association. Circulation 116, 1081-1093.

14. Sichieri R \& Everhart JE (1998) Validity of a Brazilian food frequency questionnaire against dietary recalls and estimated energy intake. Nutr Res 18, 1649-1659.

15. Nettleton JA, Schulze MB, Jiang $\mathrm{R}$ et al. (2008) A priori-defined dietary patterns and markers of cardiovascular disease risk in the Multi-Ethnic Study of Atherosclerosis (MESA). Am J Clin Nutr 88, 185-194.

16. Expert Panel on Detection Evaluation and Treatment of High Blood Cholesterol in Adults (2001) Executive summary of the third report of the National Cholesterol Education Program (NCEP) Expert Panel on Detection, Evaluation, and Treatment of High Blood Cholesterol in Adults (Adult Treatment Panel III). JAMA 285, 2486-2497.

17. Levey AS, Coresh J, Balk E et al. (2003) National Kidney Foundation practice guidelines for chronic kidney disease: evaluation, classification, and stratification. Ann Intern Med 139, 137-147.

18. Fox C, Larson MG, Hwang S-J et al. (2006) Cross-sectional relations of serum aldosterone and urine sodium excretion to urinary albumin excretion in a community-based sample. Kidney Int 69, 2064-2069.

19. Trindade IS, Heineck G, Machado JR et al. (1998) Prevalence of systemic arterial hypertension in the population of Passo Fundo (Brazil) metropolitan area. Arq Bras Cardiol 71, 127-130.

20. Freitas OC, Carvalho FR, Neves JM et al. (2001) Prevalence of hypertension in the urban population of Catanduva, in the State of São Paulo, Brazil. Arq Bras Cardiol 77, 9-21.

21. Wolf-Maier K, Cooper RS, Kramer H et al. (2004) Hypertension treatment and control in five European countries, Canada, and the United States. Hypertension 43, $10-17$.

22. Mejía-Rodríguez O, Paniagua-Sierra R, Valencia-Ortiz Mdel $\mathrm{R}$ et al. (2009) Factores relacionados con el descontrol de la presión arterial. Salud Publica Mex 51, 291-297.

23. Kramer H, Han C, Post W et al. (2004) Racial/ethnic differences in hypertension and hypertension treatment and control in the Multi-Ethnic Study of Atherosclerosis (MESA). Am J Hypertens 17, 963-970. 
24. Knight EL, Bohn RL, Wang PS et al. (2001) Predictors of uncontrolled hypertension in ambulatory patients. Hypertension 38, 809-814.

25. Roux O, Chapellier M, Czernichow S et al. (2006) Determinants of hypertension control in a large French population of treated hypertensive subjects. Blood Pressure 15, 6-13.

26. Pires CGS \& Mussi FC (2008) Crenças em saúde para o controle da hipertensão arterial. Cienc Saude Coletiva 13, $2257-2267$.

27. Cléroux J, Feldman RD \& Petrella RJ (1999) Recommendations on physical exercise training. CMAJ 160, S21-S28.

28. Fogeholm M \& Kukkonen-Harjula K (2000) Does physical activity prevent weight gain - a systematic review. Obes Rev 1, 95-111.

29. Hermansen K (2000) Diet, blood pressure and hypertension. Br J Nutr 83, Suppl. 1, S113-S119.

30. Stamler J, Vaccaro O, Neaton JD et al. (1993) Diabetes, other risk factors, and 12-yr cardiovascular mortality for men screened in the Multiple Risk Factor Intervention Trial. Diabetes Care 16, 434-444.

31. Conen D, Ridker PM, Mora S et al. (2007) Blood pressure and risk of developing type 2 diabetes mellitus: the Women's Health Study. Eur Heart J 28, 2937-2943.

32. Izzo R, de Simone $\mathrm{G}$, Chinali $\mathrm{M}$ et al. (2009) Insufficient control of blood pressure and incident diabetes. Diabetes Care 32, 845-850.

33. Coresh J, Wei GL, McQuillan G et al. (2001) Prevalence of high blood pressure and elevated serum creatinine level in the United States. Arch Intern Med 161, 1207-1216.

34. Levey AS, Bosch JP, Lewis JB et al. (1999) A more accurate method to estimate glomerular filtration rate from serum creatinine: a new prediction equation. Ann Intem Med 130, 461-470.

35. Law MR, Wald NJ, Morris JK et al. (2003) Value of low dose combination treatment with blood pressure lowering drugs: analysis of 354 randomised trials. BMJ 326, 1427-1434.
36. Fine LJ \& Cutler JA (2006) Hypertension and the treating physician: understanding and reducing therapeutic inertia (Editorial). Hypertension 47, 319-320.

37. Okonofua EC, Simpson KN, Jesri A et al. (2006) Therapeutic inertia is an impediment to achieving the Healthy People 2010 blood pressure control goals. Hypertension 47, 345-351.

38. He J, Muntner P, Chen J et al. (2002) Factors associated with hypertension control in the general population of the United States. Arch Intern Med 162, 1051-1058.

39. Bibbins-Domingo K, Chertow GM, Coxson PG et al. (2010) Reductions in cardiovascular disease projected from modest reductions in dietary salt. $N$ Engl J Med 362, 590-599.

40. Sarno F, Claro RM, Levy RB et al. (2009) Estimated sodium intake by the Brazilian population, 2002-2003. Rev Saude Publica 43, 219-225.

41. Steffen LM, Kroenke CH, Yu X et al. (2005) Associations of plant food, dairy product, and meat intakes with 15-y incidence of elevated blood pressure in young black and white adults: the Coronary Artery Risk Development in Young Adults (CARDIA) Study. Am J Clin Nutr 82, 1169-1177.

42. Wakabayashi I (2009) Impact of body weight on the relationship between alcohol intake and blood pressure. Alcohol Alcohol 44, 204-210.

43. Galea S \& Tracy M (2007) Participation rates in epidemiologic studies. Ann Epidemiol 17, 643-653.

44. Marques-Vidal P, Ruidavets J-B, Cambou J-P et al. (2002) Trends in overweight and obesity in middle-aged subjects from Southwestern France, 1985-1987. Int J Obes Relat Metab Disord 26, 732-734.

45. Gomes GJ, Seyffarth AS \& Nascimento MAB (2008) Adequação da dieta de hipertensos em relação à Abordagem dietética para Hipertensão Arterial. Com Ciencias Saude 19, 137-144. 